\title{
Improving Clinical Laboratory Quality through Reduction of Tests' Turnaround Time in Democratic Republic of the Congo: Key Strategies
}

\author{
Chabo Byaene Alain ${ }^{*}{ }^{(}$, Mabela Makengo Matendo Rostin ${ }^{2}$, Konde Nkiama Numbi Joël3, \\ Muhindo Mavoko Hypolite ${ }^{4}$, Kayembe Nzongola-Nkasu Donatien', Tanon Aristophane Koffi ${ }^{5}$, \\ Muwonga Masidi Jérémie' ${ }^{1}$, Situakibanza Nani-Tuma Hippolyte ${ }^{4,6}$
}

\footnotetext{
${ }^{1}$ Department of Medical Biology, University Hospital of Kinshasa, Faculty of Medicine, University of Kinshasa, Kinshasa, Democratic Republic of the Congo (DRC)

${ }^{2}$ Department of Mathematics and Informatics, Faculty of Sciences, University of Kinshasa, Kinshasa, Democratic Republic of the Congo (DRC)

${ }^{3}$ Department of Health and Environment, Faculty of Medicine, University of Kinshasa, Kinshasa, Democratic Republic of the Congo (DRC)

${ }^{4}$ Department of Tropical Medicine, University Hospital of Kinshasa, Faculty of Medicine, University of Kinshasa, Kinshasa, Democratic Republic of the Congo (DRC)

${ }^{5}$ Department of Dermatology and Infectiology, Faculty of Medical Sciences, Félix Houphouët Boigny University, Abidjan-Cocody, Côte d'Ivoire

${ }^{6}$ Department of Internal Medicine, University Hospital of Kinshasa, Faculty of Medicine, University of Kinshasa, Kinshasa, Democratic Republic of the Congo (DRC)

Email: ^byaene_2005@hotmail.com
}

How to cite this paper: Alain, C.B., Rostin, M.M.M., Joël, K.N.N., Hypolite, M.M., Donatien, K.N.-N., Koffi, T.A., Jérémie, M.M. and Hippolyte, S.N.-T. (2021) Improving Clinical Laboratory Quality through Reduction of Tests' Turnaround Time in Democratic Republic of the Congo: Key Strategies. Journal of Biosciences and Medicines, 9, 96-116. https://doi.org/10.4236/jbm.2021.910009

Received: September 18, 2021 Accepted: October 18, 2021 Published: October 21, 2021

\begin{abstract}
In Democratic Republic of the Congo (DRC), the laboratory TAT is significantly very long and do not comply with either international standards or the suggestions of customers. However, there is neither a national nor a local strategy to improve the laboratory TAT. The aim of the present study is to develop practical management strategies to shorten clinical laboratory tests' TAT. This was a qualitative study conducted in Kinshasa. Focus groups and Lean tools were used respectively to generate a wide range of views from a variety of laboratory staff and to eliminate several form of waste in the laboratory flow process. Based on the identified root causes of delay, focus groups participants reported that there is a lot of scope for the improvement of TAT in DRC. Consistent attendance and punctuality are essential. The hospital management should implement the Laboratory Information Systems (LIS) and install Middleware. Total laboratory automation, inventory system for all reagents and supplies used in the laboratory, expansion of the sampling area,
\end{abstract}


Copyright $\odot 2021$ by author(s) and Scientific Research Publishing Inc. This work is licensed under the Creative Commons Attribution International License (CC BY 4.0).

http://creativecommons.org/licenses/by/4.0/ sufficient number of high-power machine and a clear job description are indispensable. LIS, $3.5 \mathrm{~mL} \mathrm{BD} \mathrm{vacutainer} \mathrm{Barricor}{ }^{\mathrm{TM}}$ tube and point-of-care testing (POCT) are necessary for workflow improvement. A reduction of 312 minutes was achieved by eliminating or decreasing non-value-added activities. Applying the suggested key strategies, and particularly the new workflow process, is a basis for improving the laboratory tests' TAT. The algorithm presented can be easily implemented in other laboratories that face this type of problem.

\section{Keywords}

Turnaround Time, Quality Indicator, Quality Improvement, Clinical Laboratory, Focus Groups, Lean Management, Quality Assurance, Democratic Republic of the Congo

\section{Introduction}

The word quality has many meanings, but basically, it refers to the set of inherent properties of an object that allows satisfying stated or implied needs. According to Bergman and Klefsjö, quality means to satisfy, and preferably exceed, the needs and expectations of the customers [1]. Quality primarily is the total attribute of a product or service that causes satisfaction or contented feeling in the minds of a customer after the consumption of that product/service [2]. Quality, being a fitness for use, is an outcome of inner comparison taken place in the mind of each customer on the expectation before purchasing the service and the perception he/she got after consuming that service. When expectations are perfectly aligned with perception, service quality occurs [3]. Quality means those features of products/services, which meet customer needs and thereby provide customer satisfaction [4]. In service marketing literature, service quality is a marketing term used to convey the evaluation of fitness of services offered by an institution and to what extent it confirms to the expectation of customers [5]. Quality is defined by Wicks and Roethlein as the summation of the affective evaluations by each customer of each attitude object that creates customer satisfaction [6]. Juran defines quality means freedom from deficiencies-freedom from errors that doing work over again or that result in failures, customer dissatisfaction, and customer claims and so on [7]. As Robert Cole said, "total quality means completely satisfying customers on the full range of product and service needs. Thus, we define quality in terms of customer satisfaction" [8]. Philip Crosby, one of the founding fathers of the quality movement, states quality is an ability to satisfy needs [9]. Edwards Deming was onto something when he said that the customer's definition of quality is the only one that matters [10]. In accordance with all the above definitions of quality, we can conclude that quality means "customer satisfaction" i.e. "conformance to customer requirements" [4].

A quality indicator is a tool that enables the user to quantify the quality of a 
selected aspect of care by comparing it with a criterion [11]. Quality indicators are one of the tools of Quality Management System (QMS) used to monitor and control process functioning, whereby the data collected provide a basis for the implementation of corrective measures and continuous quality improvement [12]. For Medical Laboratory, ISO 15189:2012 requires the establishment of quality indicators to monitor and evaluate laboratory performance throughout critical aspects of pre-examination, examination, and postexamination processes [13]. Shahram Shahangian and Susan R. Snyder have identified 14 quality indicators or performance measures which were grouped according to the stage of the total laboratory testing process. These indicators are: test order appropriateness, inpatient wristband identification error, patient satisfaction with phlebotomy, specimen inadequacy/rejection, blood culture contamination, specimen container information error, proficiency testing performance, gynecologic cytology-biopsy discrepancy, inpatient laboratory result availability, corrected laboratory reports, critical values reporting, clinician satisfaction with laboratory services, follow-up of abnormal cervical cytology results, turnaround time [14]. Turnaround time (TAT) is the total amount of time required to complete a cycle of the process. In laboratory management, this cycle encloses the time from ordering a test to delivering reports to end customers. At the beginning, laboratory performance evaluation only focused on result quality including accuracy and precision. Nowadays, TAT is increasingly used as a quality indicator to assess laboratory performance. Managing TAT is important in clinical laboratories because TAT is a metric used to monitor the efficiency and productivity of a laboratory. Benefits of TAT control are so many: 1) With faster and reliable report delivery time, you have more credibility from patients, referrals, and business partners as well; 2) shorter reporting time enables doctors to take quick action on reports much faster. This improves patient service time; 3 ) improved service delivery time leads to an increase in the volume of samples processed per day; 4) Monitoring the variabilities in TAT helps laboratory managers get insights on the causes of delay. This can be useful in making improvements in different areas of laboratory processes; 5) reviewing TAT can help reduce delivery time and reduce costs in a significant manner; 6) etc. The purpose of the first study by Chabo et al. was to evaluate the quality of laboratory services and to identify priorities for quality improvement. This study revealed that the most important opportunity for quality improvement was the laboratory tests' turnaround time [15]. The second study conducted in Democratic Republic of the Congo, from October 2020 to April 2021, evaluated the laboratory tests' turnaround time (TAT) and identified reasons for delay. Four measures were used to represent TAT: mean and standard deviation (SD), median and interquartile range, $90 \%$ completion time, proportion of acceptable tests or outliers. The study results were alarming: The laboratory TAT was significantly very long and did not comply with either international standards or the suggestions (requirements) of attending physicians who are the laboratory's primary clients. The root causes of 
the delay fall into six categories and concern Machine, Management, Manpower, Material, Method and Milieu. Finally, the authors recommended that preventive and curative measures be taken to reduce the delay and improve the TAT [16]. However, to the best of our knowledge, there is neither a national nor a local strategy to improve the laboratory TAT in DRC. Therefore, based on the above results, the aim of the present study is to develop practical management strategies to shorten clinical laboratory tests' TAT.

\section{Material and Methods}

This was a qualitative study conducted in Kinshasa. The study received ethical approval from the ethical review committee of the School of Public Health of the University of Kinshasa $\mathrm{N}^{\circ}$ ESP/CE/55/2020. Focus groups and Lean tools were used in order to develop practical management strategies to shorten clinical laboratory tests' TAT.

\subsection{Focus Groups}

Focus groups were held with laboratory professionals from hospitals, academia and NGO (Non-Governmental Organisations) in Kinshasa. The objective was to generate a wide range of views from a variety of laboratory experts.

\subsubsection{Focus Group Topic Guide}

The topic guide was tailored around Key Strategies for Reducing TAT in Clinical Laboratory. The guide proceeded logically from one topic to another, and flow from the general to the specific. Questions were open-ended, simple, unbiased and non-threatening. For example, how to fight against the staff tardiness and employee absenteeism, what to do to avoid the delay in the supply of materials and reagents, how to make a good choice of devices, which is developing the job description and what is the content, ... The guide was pre-tested with several "mock" focus groups.

\subsubsection{Recruiting Participants}

Snowballing recruitment technique was used [17]. Five weeks before the focus groups, the lead author (CBA) contacted the service manager of each concerned laboratory service and provided study information sheet, consent form and a poster to recruit health professionals from within their service. Health professionals were eligible to participate if they were working in a clinical laboratory or a laboratory service for more than two years. Participants' selection was made by the service manager.

All participants received further information about the study's aims and objectives via the study information sheet. This invited them to reflect on their experience of the management of medical laboratory, and how the laboratory tests' TAT could be improved taking into account the root causes of long TAT. All participants were asked to sign a consent form before taking part in the focus groups. In the consent form, the respondents were informed of the purpose of 
the study and assured of confidentiality and their right to withdraw from the study.

\subsubsection{Number of Focus Group Sessions}

The number of focus groups held was informed by previous literature on research methodology in qualitative studies, according to which, three focus groups are sufficient to capture more than $80 \%$ of coded themes [18]. In this study, five focus groups with 35 participants (i.e. seven participants for each focus groups) were run between 20 July and 30 August 2021.

\subsubsection{Conducting a Focus Group}

Focus group interviews took place in one of the meeting rooms of each service. Participants were arranged to sit around a table to enable them to see and hear one another. CBA had the role of moderator and established a welcoming and open environment with some basic ground rules: emphasize there are no right or wrong answers to the questions, ask participants to listen respectfully to each response, have all attendees turn off cellphones, require that only one person speak at a time [19]. The moderator facilitated the conversation and prompted participants with questions to guide the discussion over topics that were relevant to the objectives of the study. Focus group interviews were audio-recorded. The recorder recorded focus group basics such as date, time, topic, number of participants; briefly summarized responses and assisted the moderator in monitoring time [19]. The time allocated for each focus group was $120 \mathrm{~min}$ (20 $\mathrm{min}$ for consenting, $80 \mathrm{~min}$ for the focus group, and $20 \mathrm{~min}$ for debriefing).

\subsubsection{Debriefing}

Participants took this opportunity to begin summarizing themes presented during the conversation. They spent 15 - 20 minutes after the session to debrief and review the notes. The recorder finalized a summary of overall themes, provided a summary of responses for each questions, proofreaded and edited the report to ensure accuracy and clarity.

\subsubsection{Data Analysis}

Content analysis was performed using NVivo 10, which is a computer-assisted/ aided qualitative data-analysis software. Action plans were prioritized according to those solutions that were "quick wins", to reduce TAT.

\subsection{Lean Tools}

The focus of Lean in the present study was to improve the workflow process and reduce processing time. The current-state value stream map defining the process of laboratory analysis and identifying all of its components was created in a previous study (Figure 1). This study showed that the mean total TAT was $464.4 \pm$ 31.05 minutes for hemogram; $549.1 \pm 29.9$ minutes for glucose; $483.1 \pm 7.32$ minutes for urea; $481 \pm 6.2$ minutes for creatinine; $536.7 \pm 30.1$ minutes for electrolytes. Major areas in which delays occurred were pre-analytical phase 


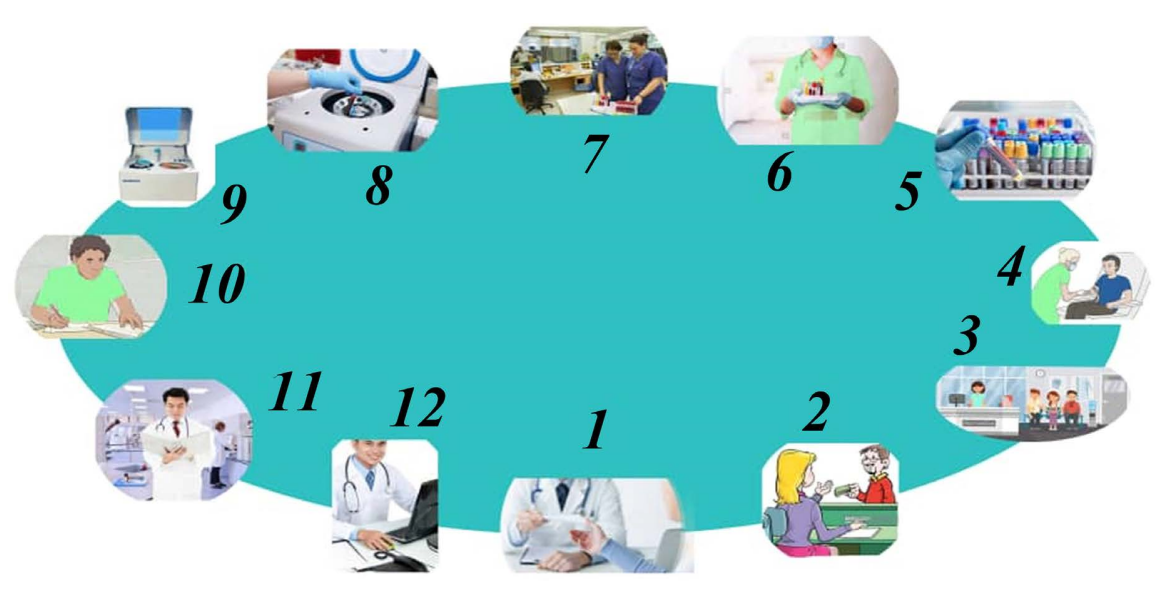

Figure 1. Current value stream mapping.

(70\%) and post-analytical phase (25\%). The processing steps that caused the most delays in TAT were patient reception (32\%), sample assemblage (28\%) and biological validation (15\%) [16]. Workflow improvements consisted in reducing the TAT according to the customers' suggestion i.e. $<120$ minutes or international standards i.e. $<60$ minutes. This was done in two steps. The first step consisted from identifying and eliminating wastes i.e. non-value-added steps in the workflow process. The current Value Stream Mapping was reviewed in detail by the focus groups participants to identify waste (i.e., non-value-added activities) that could be eliminated and identify opportunities to minimize potential for errors. The team then brainstormed potential solutions to address activities or process steps identified as non-value-added and to maximize value-added activities. The definitions of value-added and non-value-added activities were based on Lean principles, whereby assigning value to process steps is directly related to the benefit to the customer. Value-added activities were those activities that directly contributed to patient's specimen processing, such as phlebotomy, sample analysis, and result's validation. Non-value-added activities were those activities that were considered duplication of work or not directly contributing to patient's specimen processing. The following is a summary of these wasteful activities: overproduction, inventory, motion, transportation, over-processing, defects, waiting, under-utilizing [20]. During analysis of the process, the team focused on steps that were categorized as waste, particularly those steps that took long periods (highlighted in the value stream mapping). From these raw data, the moderator developed visual graphs that demonstrated to the team how much time was spent in non-value-added activities (i.e., waste) such as storage (i.e., waiting for the next step), transportation, inspection, and certain processing steps. Participants also discussed the ideal future state and identified opportunities for improvement. The second step was to draw the future state map that shows how the process of laboratory analysis should be done after the wastes and inefficiencies have been removed. The future state map was created based on answering a collection of questions on topics relevant to efficiency and implementing technical issues related to lean techniques. Finally, the suggested map 
was applied as a basis for making essential changes to the system: a new process was then designed based on the identified opportunities.

\section{Results}

Five focus groups were conducted with 35 staff members in total.

Table 1 shows the socio-demographic characteristics of focus groups participants.

There were 35 total focus groups participants; 21 (60\%) were male and 14 (40\%) were female; 28 (80\%) were hospital professional i.e. medical biologist (physicians) or laboratory technicians, 4 (11.4\%) were academia professional, 3 (8.6\%) were NGO professional. Academia professional and NGO professional were management experts.

Table 2 shows the key strategies for reducing TAT in clinical laboratory. These root cause based strategies were developed by focus group participants.

Figure 1 shows the Current Value Stream Mapping (VSM) defining the process of laboratory analysis and identifying all of its components. This is a snapshot capturing how the process is currently being done.

The laboratory process was divided into three phases. The preanalytic phase included steps 1 (Laboratory tests' ordering), 2 (Laboratory tests' billing and payment), 3 (Patient reception), 4 (sampling = phlebotomy), 5 (sample assemblage), 6 (transit to laboratory), 7 (reception and sorting) and 8 (sample preparation). The analytic phase was the step 9 (Manual or automatically sample analysis). The postanalytic phase included steps 10 (Result reporting), 11 (Biological validation) and 12 (Making the results available). Steps 1 and 2 are extra-laboratory. Intra-lab TAT begins by step 3 .

Table 1. Socio-demographic characteristics of focus groups participants.

\begin{tabular}{ccc}
\hline Socio-demographic characteristics & $\mathbf{n}$ & $\%$ \\
\hline Gender & 21 & 60 \\
\hline Male (M) & 14 & 40 \\
\hline Age (years) & & 11.4 \\
\hline $18-27$ & 4 & 20 \\
$28-37$ & 7 & 40 \\
$38-47$ & 14 & 17.2 \\
$48-57$ & 6 & 11.4 \\
$\geq 58$ & 4 & 8.6 \\
\hline Profession & 28 & 80 \\
\hline Academia professional & 4 & 11.4 \\
\hline Hospital professional & 3 & \\
\hline
\end{tabular}


Table 2. Root causes-based key strategies for reducing TAT in clinical laboratory.

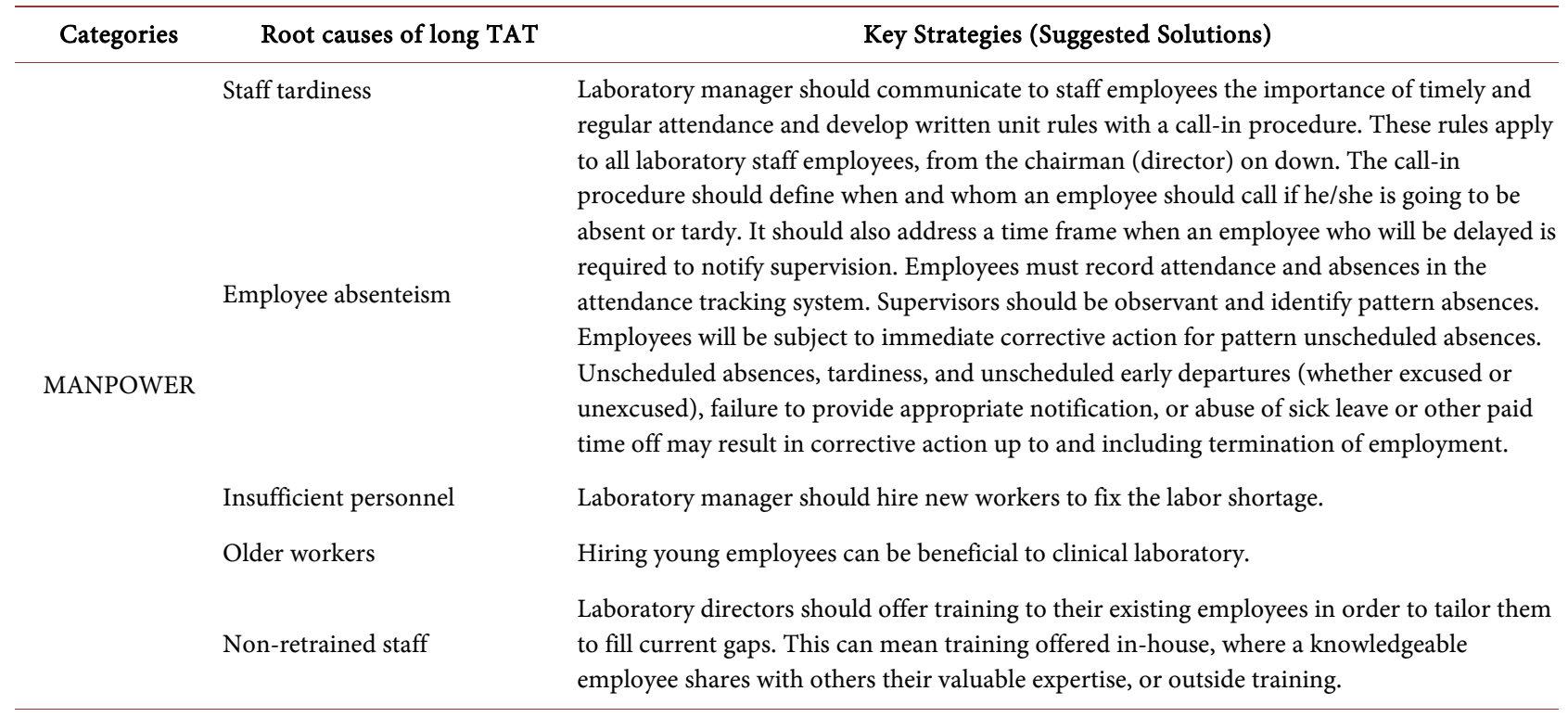

Insufficient number of machines

Laboratory directors should provide sufficient number of machines that meet the operational requirements.

Defective machines

MACHINE

Not maintained machines

Low-power machines

Non-existent job description

\section{MANAGEMENT}

Delay in the supply of materials

Poor choice of device

Lack of sanctions or impunity

Reagent out of stock

MATERIAL

Syringue not provided

Micropipette not calibrated

Lack of material supply

Lack of running water

MILIEU Heat in the laboratory

Small sample collection room
The technical director of the laboratory should repair damaged machines or replace them altogether with new ones. He must ensure that a back-up is provided for broken machines.

Good maintenance habits and an effective repair system will minimise the amount of time equipment is unusable. The Technical Director is responsible for this.

The laboratory should acquire high-powered machines which are capable of developing a large amount of work in a short time.

Job descriptions should reflect all skills needed and accurately describe tasks, roles, and authorities. Critical competencies for each task should be identified. First-line supervisors should be involved in this step.

Stocks must be properly assessed: this involves defining a minimum stock level, which once reached triggers replenishment. The laboratory's stock manager must analyze the remaining stock and issue in order to bring it up to the maximum authorized stock level.

The hospital management should involve experts who have knowledge of laboratory tools in the selection of laboratory equipment.

Laboratory manager should establish standards and rules that all laboratory personnel should observe and predict the sanctions for recalcitrant.

Laboratory should have a system for inventory maintenance and purchasing.

The technical department of the hospital should set up a drinking water supply system and ensure that there is no shortage of good quality water in the laboratory.

The hospital's technical department should establish a system to maintain the temperature and humidity of the laboratory within acceptable ranges.

The hospital management should expand the sampling area and increase the number of beds and staff. 


\section{Continued}

Lack of automation

METHODS
The hospital management should implement the total laboratory automation.

The hospital management should implement the Laboratory Information Systems (LIS) and install Middleware. Then, the laboratory manager should reorganize the laboratory process flow to eliminate non-value-added steps or waste (see Figures 1-4).

Figure 2 shows the value-added time (black) and non-value-added time (red) as percentage of overall processing time.

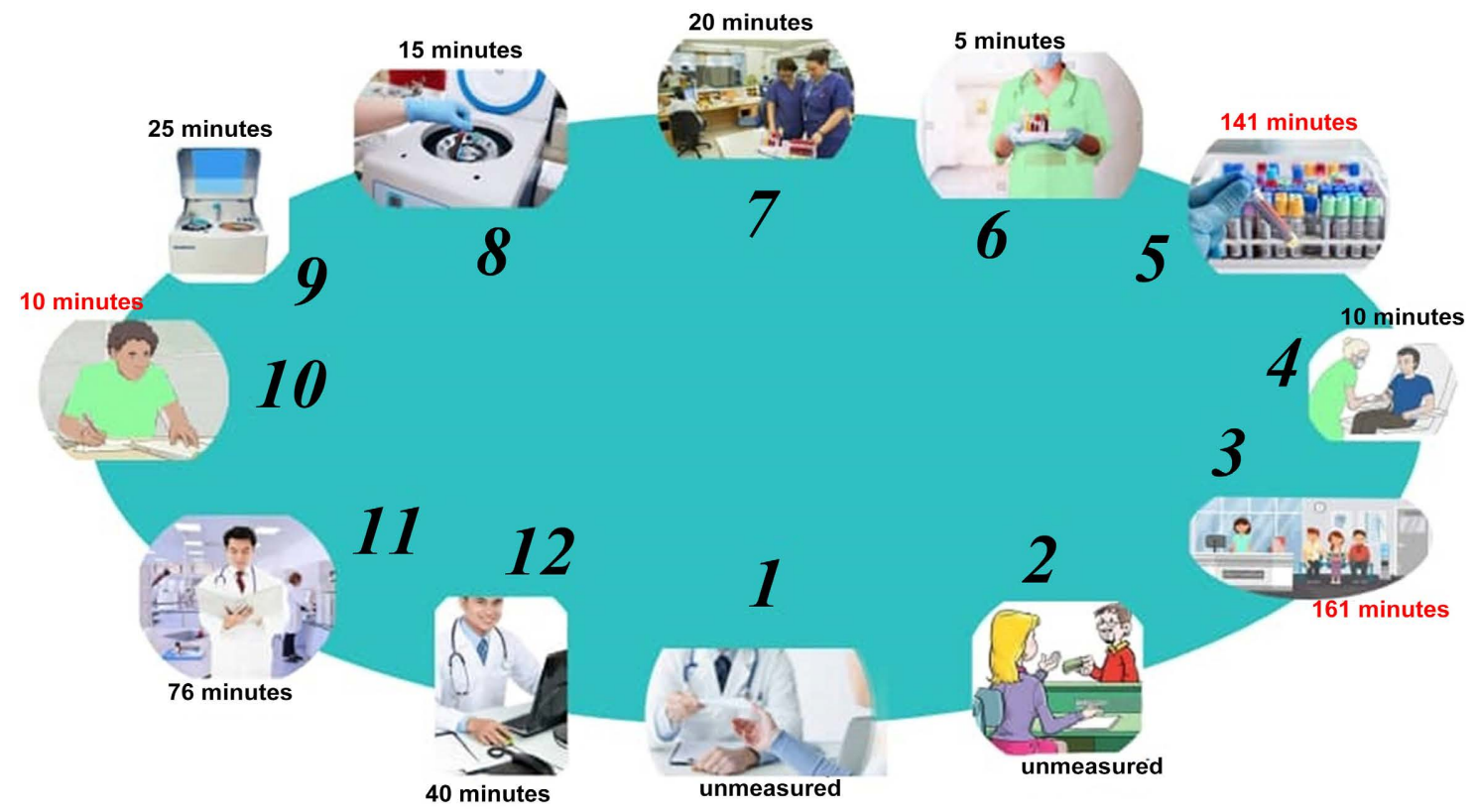

Figure 2. Time line analysis pie chart of process steps showing value-added time (black) and non-value-added time (red) as percentage of overall processing time. Steps: 1 = Laboratory tests' ordering; 2 = Laboratory tests' billing and payment; 3 = Patient's reception; $4=$ sampling or phlebotomy; $5=$ sample's assemblage; $6=$ transit to laboratory; 7 = reception and sorting; $8=$ sample's preparation; $9=$ manual or automatically sample's analysis; 10 $=$ Result's reporting; $11=$ Biological validation; $12=$ Making the results available.

Figure 2 is a pie chart that shows value-added and non-value-added time as a percentage of overall Processing Time. This graph clearly demonstrates that most of the Processing Time in the current state was spent in non-value-added activities, and these should be the potential targets for the improvement strategy. Figure 2 shows the current workflow with the specific steps that were believed to be wasted activities highlighted in red. It was determined that $62 \%$ (312 minutes out of 503 minutes) of the intra-laboratory overall mean TAT was spent in non-value-added activities, which are patient reception (patients are waiting for phlebotomy in a waiting room), sample assemblage (the samples taken are recorded in a laboratory book and placed in a rack, waiting for large batch sizes) and Result reporting (Results issuing from the laboratory analysis are completed by the technologist on the Clinical Laboratory Reporting Form. This is a duplication of work because the information is recorded on both the reporting form and in the laboratory book before the record in the database). 


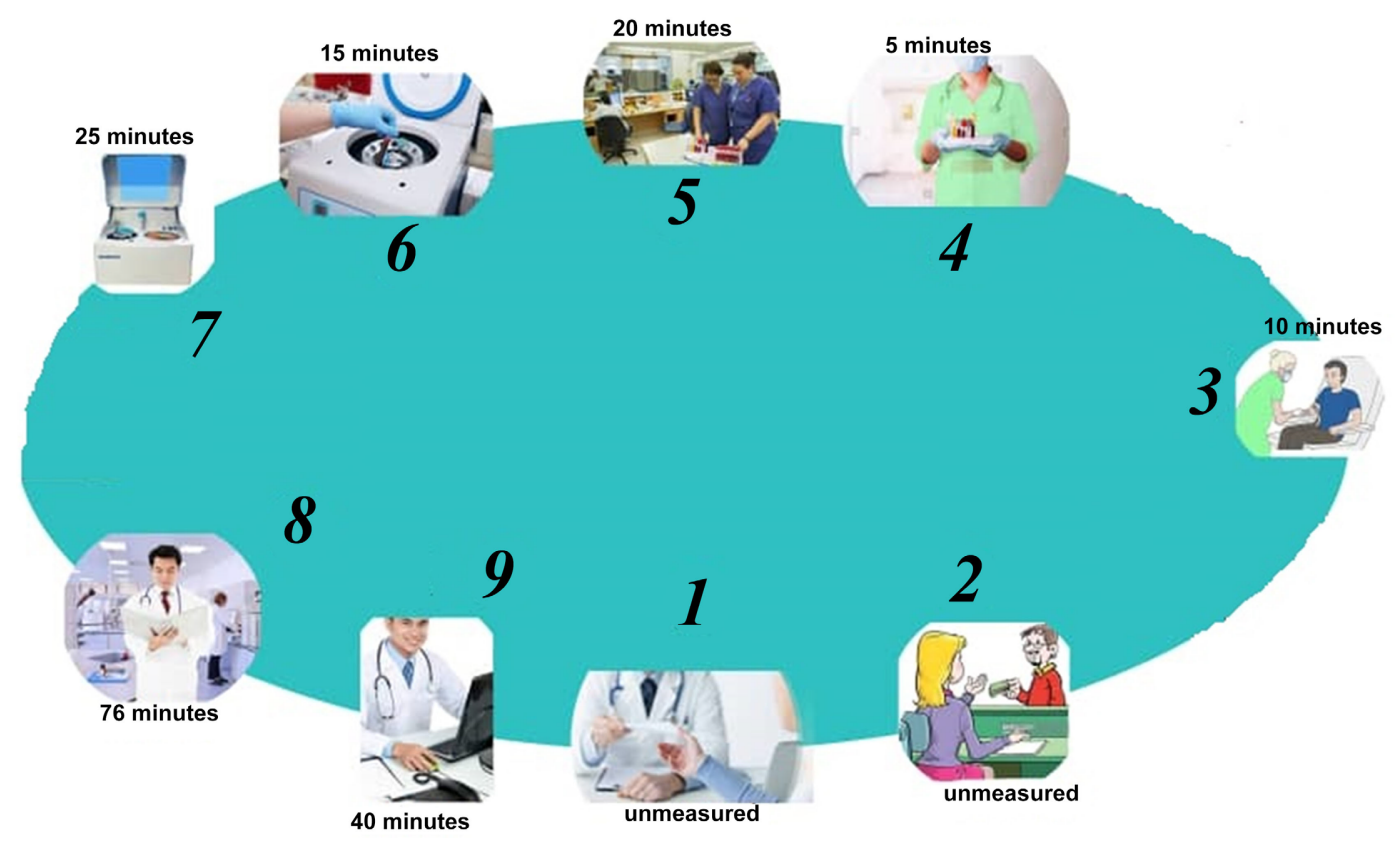

Figure 3. Process flow after eliminating the non-value-added steps. Steps: 1 = Laboratory tests' ordering; 2 = Laboratory tests' billing and payment; $3=$ sampling or phlebotomy; $4=$ transit to laboratory; $5=$ reception and sorting; 6 = sample's preparation; $7=$ manual or automatically sample's analysis; $8=$ Biological validation; 9 = Making the results available.

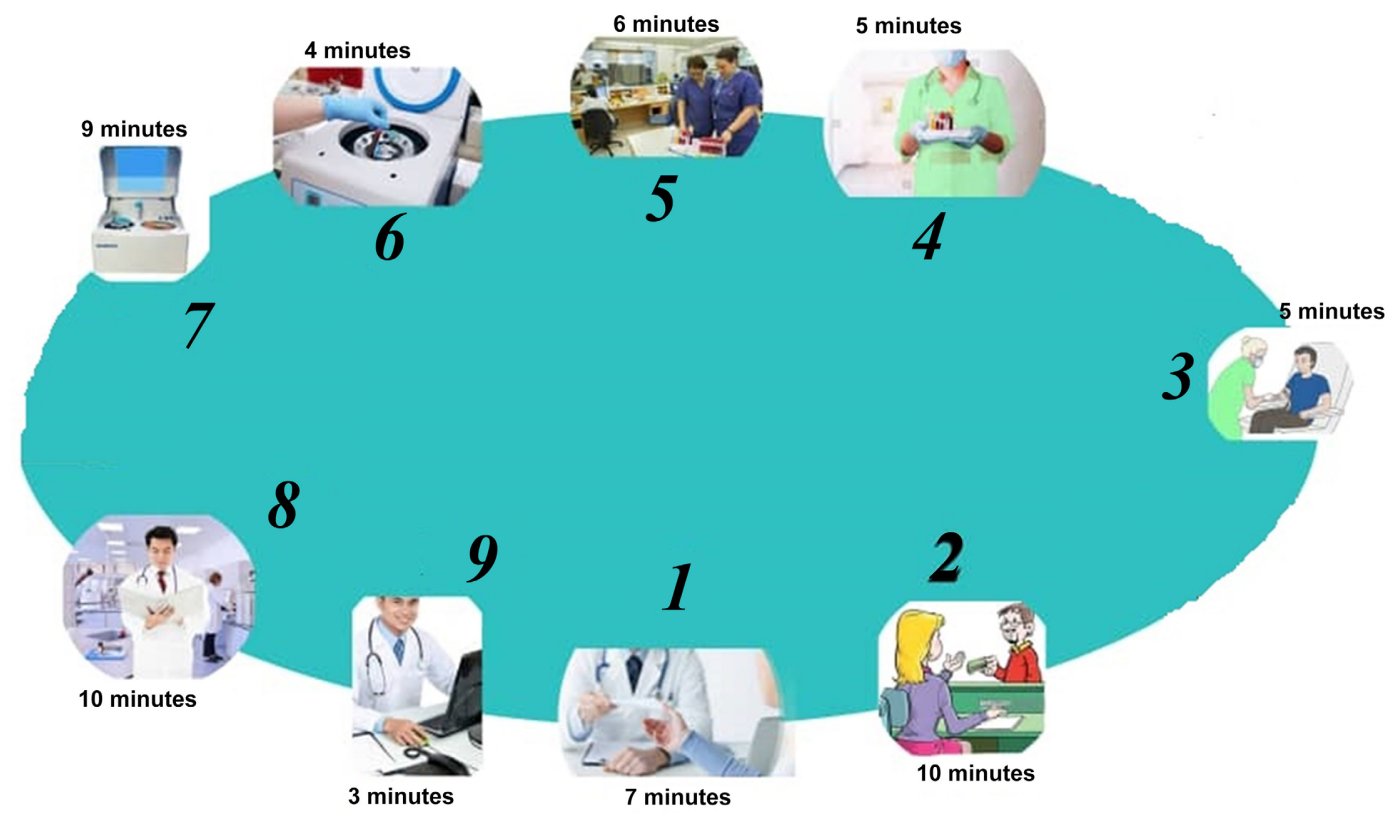

Figure 4. Improved workflow subsequent to waste elimination and opportunities identification. Steps: $1=$ Laboratory tests' ordering; 2 = Laboratory tests' billing and payment; 3 = sampling or phlebotomy; $4=$ transit to laboratory; 5 = reception and sorting; 6 = sample's preparation; 7 = automatically sample's analysis; 8 = Biological validation; 9 = Making the results available.

Figure 3 shows the process flow after eliminating the wastes i.e. the non-valueadded steps.

After waste elimination, the intra-laboratory TAT decreased from $503 \mathrm{mi}$ - 
nutes to 191 minutes (>120 minutes). Other operational improvements must be implemented in order to reduce the overall TAT according to customers' suggestion ( $<120$ minutes) or to international standards ( $<60$ minutes). Improvement opportunities which were identified included the following (Table 3 ).

Objectives and key strategies for workflow improvement are presented in $\mathrm{Ta}$ ble 3.

After waste elimination and improvement opportunities identification, a new process was then designed based on the identified opportunities (Figure 4). Changes introduced to the process are presented in Table 3.

Improved workflow subsequent to waste elimination and opportunities identification is presented in Figure 4.

Note the reduction in steps as compared with Figure 2 (9 steps instead of 12) and the reduction in total time as compared with Figure 3 (59 minutes instead of 191 minutes).

\section{Discussion}

To improve turnaround time in the laboratory is an important benchmark that all medical laboratories strive for. The current study used Focus groups and Lean tools in order to develop practical management strategies to shorten clinical laboratory tests' TAT. Research has demonstrated that focus groups are an effective way to obtain a diverse range of information to improve some specific product or service or, more globally, during the development of strategic plans

Table 3. Objectives and key strategies for workflow improvement.

\begin{tabular}{|c|c|c|}
\hline Step & Objective & Key strategy to achieve the objective \\
\hline 1 & Test requesting: $\leq 7$ minutes & The test requesting will be made online. The laboratory will be computerized. \\
\hline 2 & Laboratory tests' billing: $\leq 10$ minutes & The number of counter for the payment of fees will be increased: 4 counters instead of just one. \\
\hline 3 & $\begin{array}{l}\text { Sampling: } \leq 5 \text { minutes instead of } 10 \\
\text { minutes }\end{array}$ & $\begin{array}{l}\text { The sampling area will be expanded: } 30 \text { square meters instead of } 12 \text { square meters. The number of } \\
\text { beds and phlebotomists will be increased: } 7 \text { instead of } 3 \text {. }\end{array}$ \\
\hline 4 & $\begin{array}{l}\text { Transport and distribution of collected } \\
\text { samples: } \leq 5 \text { minutes }\end{array}$ & $\begin{array}{l}\text { The staff responsible for transporting the samples will be on time and steady. Absences, tardiness, } \\
\text { and early departures may result in corrective action up to and including termination of } \\
\text { employment. In addition, it will be necessary to install a satellite laboratory. }\end{array}$ \\
\hline 5 & $\begin{array}{l}\text { Reception and sorting: } \leq 6 \text { minutes } \\
\text { instead of } 20 \text { minutes }\end{array}$ & $\begin{array}{l}\text { The staff responsible for receiving the samples and verifying their compliance will be punctual } \\
\text { and regular. Unscheduled absences, tardiness, and unscheduled early departures (whether } \\
\text { excused or unexcused) will be severely penalized. }\end{array}$ \\
\hline 6 & $\begin{array}{l}\text { Sample preparation procedure: } \leq 4 \\
\text { minutes instead of } 15 \text { minutes }\end{array}$ & $\begin{array}{l}\text { Centrifugation time will be reduced using } 3.5 \mathrm{~mL} \mathrm{BD} \text { vacutainer Barricor }{ }^{\mathrm{TM}} \text { tube centrifuged } 3 \\
\text { min at } 4000 \times \mathrm{g} \text {. }\end{array}$ \\
\hline 7 & $\begin{array}{l}\text { Sample analysis: } \leq 8 \text { minutes instead of } \\
25 \text { minutes }\end{array}$ & $\begin{array}{l}\text { Laboratory will implement the point-of-care testing (POCT). The POCT will be used in satellite } \\
\text { laboratories. In the central laboratory, personnel will use high-powered automatons which are } \\
\text { able to analyze several samples of patients in a short time. }\end{array}$ \\
\hline 8 & $\begin{array}{l}\text { Biological validation: } \leq 10 \text { minutes } \\
\text { instead of } 76 \text { minutes }\end{array}$ & $\begin{array}{l}\text { The number of doctors responsible for this work will be increased: } 2 \text { doctors per unity instead of } \\
\text { just one per } 4 \text { unities. }\end{array}$ \\
\hline 9 & $\begin{array}{l}\text { Making the result available: } \leq 3 \text { minutes } \\
\text { instead of } 40 \text { minutes }\end{array}$ & $\begin{array}{l}\text { The doctor who validated the results is also the responsible for recording in the validated results } \\
\text { on the computer to constitute a database. }\end{array}$ \\
\hline
\end{tabular}


or mission statements [21]. Focus groups are an important tool in strategies development and evaluation, as they provide the contextual information necessary for a program that meets the needs of the population in focus [22]. Focus groups showed dimensions of understanding that often remain untapped or inaccessible by other forms of data collection [21]. Results from focus groups enable quality assurance practitioners to provide better remedial action plans [19]. Considering the social distancing and isolation policy due to COVID-19 pandemic, online focus groups via a web videoconferencing platform (Zoom, Google meets, Kudo, ...) could be a useful way of eliciting public views related to matters of long TAT, particularly from diverse and geographically dispersed participants [23]. But, taking into account the problems related to poor technology in DRC, focus group interviews took place in one of the meeting rooms of each service. In this study, the strategies resulting from the focus group addressed the six root causes of the long TAT which were identified in a previous study [16].

The first root cause related to manpower. Human resources being part of the four factors of production is something that can not be overlooked at any organization. Personnel are the most important laboratory resource [24]. It is vital to the Clinical Laboratory for all employees to have reliable attendance: employees are expected to arrive at work punctually and to be at work during the time they are scheduled to work. Absenteeism, tardiness and job abandonment negatively impact laboratory personnel ability to effectively provide services to customers. Patients specimen processing is an activity that comprises many steps and involves many people. Therefore, one employee tardiness or absences, either in duration or frequency, can have a ripple effect on other employees and on the entire operation. For instance, an entire work batch can be delayed, setting back reporting of patient tests' results. Consistent attendance and punctuality is essential to staying current with work and to performing jobs well. Staff employees must arrive and be prepared to commence work at their scheduled start time. To clear the high volume during a short period, technical staff on the early morning shift are requested to stay in the technical area to perform tests. Quality system essential personnel involves recruiting, hiring, and retaining an adequate number of qualified, well-trained, and competent laboratory personnel to perform and manage the activities of the laboratory [25]. African laboratories are affected by lack of training [26]. Broader knowledge, skills, and competencies in best practices are essential in implementing innovative strategies to improve the quality of laboratory testing in resource limited environments like the DRC. Studies have shown that education and training of laboratory personnel improves the quality of test results and clinicians' trust in the laboratory and their subsequent willingness to remain in an under-developed area for a longer time [27] [28]. An efficient laboratory can dramatically reduce waiting time to get results and leads to faster and better health care delivery. One need in clinical laboratories today is to develop workers to carry out new and highly complex procedures. These workers must also learn to use new automated testing equipment and master the theories behind the new tests involved while developing 
new the skills [29]. A study done in Sweden also pointed out the effectiveness of in-service training to equip trainees with the new knowledge and skills required for the job [30]. Another systematic review emphasized the importance of training to health professionals to enrich their pre-existing knowledge and skills [31].

The second root cause of delay related to machine. The most important advantage of laboratory machines is a considerable acceleration and facilitation of work procedures in laboratories. Clinical and analytical laboratories are under constant pressure to increase throughput. Throughput is the amount of material or items passing through a system. In this case, it's analyzing a higher volume of samples per day. This brings several advantages: reduced cost per sample, decreased sample turnaround time, fewer instruments needed, and reduction of laboratory space required. These reasons, among others, are why laboratory managers are pushing instrument manufacturers to increase their throughput. High-throughput machines are indispensable for TAT reduction.

The third root cause of delay was in management, primarily the non-existence of the job description. Previous studies revealed that many of the hiring mistakes companies make are the result of not having a clearly defined description of what the company really wants the new applicant to do [32]. A well-written job description should assure that all parties involved, including the head of the company, the applicant, and the supervisors, understand what the positions entails and share the same expectations. Being a medical company, a clinical laboratory should have a well-written job description. A job description will not only inform an employee about the laboratory's expectations of him or her, but it also will help managers to supervise and appraise performance and determine compensation categories. A precise job description will assist interviewers by keeping them focused on the duties of the job and skills required. In addition to assisting in recruitment and selection, the job description will help guide the laboratory management in determining proper compensation and in developing training programs to meet the standards set in the job description [32].

The delay in the supply of laboratory materials was the fourth leading cause of long TAT. In implementing an inventory management system, the laboratory must assign responsibility for the programme, analyze the needs of the laboratory and establish the minimum stock needed for an appropriate time period. Appropriate logs and forms will be needed, as well as a procedure for receiving, inspecting and storing supplies. The laboratory will need to maintain an inventory system for all reagents and supplies used in the laboratory [24]. This system must include all areas where reagents and supplies are stored, the maximum number of samples that can be processed per hour, the number of samples that can be loaded at a single time, and the numbers of reagent containers and assays that can be stored onboard.

The long TAT was also due to the smallness of the sampling room (fifth root cause). This in itself also contributed to longer waiting times for patients. The area designated for outpatient phlebotomy must be as large as possible in order 
to create a patient-friendly space and provide privacy and comfort for the phlebotomy service. The phlebotomist should work in a quiet, clean, well-lit area, whether working with outpatients or inpatients [33]. The number of rooms, beds and phlebotomists should be sufficient to handle the demand at peak hours.

The latest root cause of delay concerned the long-running workflow. The focus of Lean in the present study was to improve the workflow process and reduce processing time. Lean thinking is a time-based philosophy that focuses on creating value for the customer by eliminating several forms of waste including: defects (waste from a product or service failure to meet customer expectations), overproduction (waste from making more product than customer demand), waiting (waste from time spent waiting for the next process step to occur), unused talent (waste due to underutilization of people's talents, skills, and knowledge), transportation (wasted time, resources, and costs when unnecessarily moving products and materials), inventory (waste resulting from excess products and materials that aren't processed), motion (wasted time and effort related to unnecessary movements by people) and extra-processing (waste related to more work or higher quality than is required). This philosophy aims at continually reducing the time from client order arrival until delivery with the smallest cost and highest quality. Simply put, Lean is focused on the elimination of waste, or non-value-added activities, from the process [34]. Value Stream Mapping (VSM) is a useful tool of Lean Manufacturing to reduce the wastage in any process by segregating Value Added (VA) and Non-Value Added (NVA) activities. VSM is a graphical Lean tool that integrates the materials and information logistical flows by using normalized icons in a chart, showing a "Big Picture Mapping" of the value stream [35]. Jones and Womack define VSM as the process of mapping the flow of information and materials as they are in a graphical manner and preparing a future state map with better methods and performance [36]. Finality of VSM is to suggest an as-is and to-be state map that will be applied as a basis for making essential changes to the system [37]. Thus, in the present study, to generate the strategies for improving the flow of samples, the focus groups participants first retraced the current VSM (Figure 1 and Figure 2). This mapping made it easy to read, as well as an understanding of the process and the identification of areas for improvement. Then, the participants determined the operational objectives and defined the desired situation, i.e. the future state which will have to correspond to international standards or to customer requests. A new VSM has been traced. Finally, the team defined the actions required to arrive at the future state.

Key strategies to arrive at the future state are development of laboratory information management system referred to by the acronym LIMS or LIS, $3.5 \mathrm{~mL}$ $\mathrm{BD}$ vacutainer Barricor ${ }^{\mathrm{TM}}$ tube and point-of-care testing (POCT). An appropriately designed and installed LIS brings accuracy and accessibility to the flow of samples and data in the clinical laboratory. The paper requisition will be replaced by the electronic requisition for inpatients and outpatients' orders. A 
complete computerized information system will be able to handle all the basic information management needs. A computer system has the capacity to quickly and easily manage, analyze and retrieve data. The computerized system offers some definite advantages over paper-based systems such as error reduction, quality control management, provision of options for data searching, Access to patient information, Generate reports, Ability to track reports, Ability to track and analyze trends, improved capability for maintaining patient confidentiality, Financial management, Integration with sites outside the laboratory [24]. Among process involved in lab TAT, the centrifugation is one of them that can be modulated. Centrifugation is a consuming time step which participates to increase the turnaround time (TAT) in laboratories. Reduction of centrifugation time could reduce the lab TAT. Moreover, during the pre-analytical step in the lab, centrifugation setting could also generate hemolysis according to a higher speed or higher time used. In all case, hemolysis sample should need a re-sampling and delayed management of patients. Replacing regular tubes with the low vacuum BD Barricor ${ }^{\mathrm{TM}}$ tubes has two advantages which are a reduction of centrifugation time allowing improvement of lab TAT and a reduction of hemolyzed samples that improve sample and result quality. A study by Badiou et al. evaluated the impact of replacing $4 \mathrm{~mL}$ BD vacutainer heparin lithium tubes with 15 $\mathrm{min}$ at $2000 \times \mathrm{g}$ as centrifugation setting by low vacuum $3.5 \mathrm{~mL} \mathrm{BD}$ vacutainer Barricor $^{\mathrm{TM}}$ tube centrifuged $3 \mathrm{~min}$ at $4000 \times \mathrm{g}$. A significantly reduced TAT and a significative decrease in hemolysis rate were observed with the reduction time of centrifugation allowed by use of Barricor ${ }^{\mathrm{TM}}$ tubes compared to regular heparin lithium tubes [38]. Another study evaluated the impact of BD Vacutainer ${ }^{\otimes}$ Barricor $^{\mathrm{TM}}$ Tube (Barricor ${ }^{\mathrm{TM}}$ ) on laboratory efficiency by measuring its effect on TAT and sample quality, as well as evaluate potential cost opportunities resulting from improved sample quality. By implementing Barricor ${ }^{\mathrm{TM}}$, researchers saw a significant reduction in TAT and a reduction in fibrin-related remediation time and costs, when compared to a predominant serum workflow. In fact, Barricor $^{\mathrm{TM}}$ significantly reduced the median TAT, especially for routine-priority samples during peak-hours. The TAT key-performance-indicator (percentage of results available within $90 \mathrm{~min}$ ) improved to $>90 \%$ for STAT as well as routine priority samples. Converting from serum gel, Barricor ${ }^{\mathrm{TM}}$ reduced fibrin-related remediation activities from $2.3 \%$ to $0.4 \%$. This resulted in remediation-related cost reduction of $€ 6.01047$ over the study period [39]. Another study evaluated the effects of using the Barricor tube in a stat (statin) laboratory on the results and TAT of routine chemical tests. Reseachers verified the impact of Barricor tube on reducing TAT and providing results similar to those obtained using serum separator tubes (SSTs). As results, the Barricor tube showed allowable differences compared with the SST. After introducing the Barricor tube, TAT was reduced owing to decreased centrifugation time and clogging-related problems. Hence, the study concluded that the Barricor tube is an alternative to SST for routine chemical tests in institutions aiming to reduce TAT, with clinically al- 
lowable differences in test results [40].

Implementation of point of care testing (POCT) has been suggested for analytes that have a required reporting TAT of $<30$ minutes [41]. Kendall et al. demonstrated a significant decrease in time to medical decision making for a number of patients that received hematologic, biochemical, and arterial blood gas testing after the implementation of point-of-care testing [42]. Kilgore et al. also demonstrated a decrease in therapeutic TAT using the point-of-care option [43].

Transport is one of the wastes of Lean and should be removed from the new VSM or improved by the use of pneumatic tubes. The pneumatic tube system (PTS) significantly reduces laboratory TAT, and for this reason, the PTS has been used frequently for the transport of patients' samples to the central laboratory [44]. Nevertheless, this technology is expensive and inaccessible for the majority of laboratories in the DRC. The focus group participants have developed strategies that are realistic and achievable in the current context of the country. The implementation of pneumatic tubes is very difficult and even impossible for the majority of laboratories in the DRC. However, the solution to the problem of transport may be the decentralization of laboratory services in satellite laboratories. The objective of creating a satellite laboratory is to provide adequate TAT for critical tests in emergency situations. Steindel and Howanitz realized that the TAT of satellite laboratories installed near critical care units or emergency departments in hospitals is similar to those institutions that introduce an optimized transport system to limit or reduce transport time [45]. There is some evidence that installation of a satellite laboratory may shorten laboratory TAT. The main purpose of the study by Hamdan et al. was to determine the advantages of having a satellite laboratory in an oncology outpatient treatment unit. Moreover, this study assessed whether the presence of a satellite laboratory could help reduce laboratory TAT and chemotherapy waiting time for cancer patients. The laboratory TAT and chemotherapy waiting time were analyzed and compared before and three years after the establishment of the satellite laboratory. The mean laboratory TAT decreased from one hour and 30 minutes at baseline in 2012 to 43, 43, and 37 minutes in 2013, 2014, and 2015, respectively; a reduction rate of 59\%. Mean chemotherapy waiting time also reduced, from a 2012 baseline of 252 minutes to 170, 157, and 146 minutes in 2013, 2014, and 2015, respectively; a reduction rate of $42 \%$ [46]. A prospective cohort study aimed at measuring the impact of a satellite laboratory upon laboratory result TATs and clinical decision making times. The data were collected over a six-week period before the laboratory was opened, and a subsequent six-week period. The time to haematology (blood count) results in the intervention group decreased by 47.2 minutes (95\% CI 38.3 to $56.1, \mathrm{p}<0.001$ ) after the laboratory was opened. Similar sized differences were also seen for haemostasis (d-dimer) testing 66.1 (41.8 to 90.4) minutes compared with $-14.2(-47.1$ to 18.7$)$ and chemistry 41.3 (30.3 to 52.2) compared with -4.2 ( -17.4 to 8.9$)$ testing. Decisions to discharge patients 
were significantly faster $(28.2$ minutes, 13.5 to $42.8, \mathrm{p}<0.0001)$ in the intervention group after the laboratory was opened (controls; -2.6 minutes -27.0 to 21.7) [47]. Another study evaluated the impact of a satellite laboratory on TAT for the emergency department and concluded that a satellite laboratory in the emergency department can significantly reduce laboratory TAT [48]. Lewandrowski et al. described an average reduction of 51.5 minutes in test TAT, an emergency department patient length of stay reduction of 41 minutes and an increase in physician satisfaction [49]. Many of the satellite laboratories in DRC will function 24 hours a day, 7 days a week. They will usually perform stat hematology, chemistry, urinalysis, and even immunochemistry procedures. Test menus will be limited in these satellite laboratories: procedures they will not perform will be performed in the central laboratory of each hospital. Satellite laboratories in many cases will use POCT instrumentation, especially for blood glucose testing and urinalysis.

\section{Potentials and Limitations}

The limitations of the current study are similar to those previously identified. A fundamental disadvantage of focus groups is its susceptibility to bias, because group and individual opinions can be swayed by dominant participants or by the moderator [21]. However, to the best of our knowledge, this is the first project within the hospital setting in DRC to identify strategies for TAT improvement and to apply Lean principles to the workflow processes of clinical laboratory.

\section{Conclusion}

When faced with the challenge of improving TAT within the clinical laboratory, focus groups interview were conducted involving policy elites who had previously participated in decision-making processes for health policy. Results from focus groups enabled quality assurance practitioners to provide better remedial action plans. Suggested strategies should be implemented as parts of laboratory management; that not only reduces the overall TAT but also ensures convenient diagnostic services for end-customers.

\section{Recommendations}

It is evident from the results of our study that the proposed strategies and particularly the reorganization of laboratory process flow improve laboratory quality, increasing effectiveness and efficiency. Therefore, policy makers, healthcare providers and, consequently, laboratory managers need to take into account the suggested strategies to improve clinical laboratory quality. Even though Lean Healthcare is not free from difficulties, including adjustments in transferring the principles and tools to a new setting, as well as methodological restrictions at the implementation phase [50] [51], this work is easily replicable to other laboratories that need to improve their tests' TAT. The modified sample workflow process can be easily implemented in other laboratories that face this type of 
problem. The suggested strategies can also be adapted to other clinical laboratories faced by long TAT. In general, the application of such strategies is particularly interesting and relevant as the problem of long TAT increases in DRC. The successful implementation of lean or any other improvement framework requires that the hospital and medical leadership all be strong supporters of the methodology, speak the same process improvement language, and are able to generate support and resources [52]. The effect of the changes will be evaluated by measuring the TAT before and after the implementation of the modified sample flow.

\section{Acknowledgements}

We thank Professors Ngo Bebe Dosithée and Kwilu Nappa Fulbert (Department of Health System Management, Kinshasa School of Public Health, University of Kinshasa, Kinshasa, Democratic Republic of Congo) for their advices and encouragement. We also thank focus group participants for agreeing to participate in the meetings and anyone who contributed towards the article, but does not meet the criteria for authorship.

\section{Conflicts of Interest}

The authors declare that there is no conflict of interest.

\section{References}

[1] Bergman, B. and Klefsjö, B. (1994) Quality: From Customer Needs to Customer Satisfaction. McGraw-Hill, New York.

[2] Charantimath, P.M. (2011) Total Quality Management. 2nd Edition. Pearson, London.

[3] Fitzsimmons, J.A. and Fitzsimmons, M.J. (1994) Service Management for Competitive Advantage. McGraw-Hill, New York.

[4] Poonia M.P. and Sharma S.C. (2018) Total Quality Management. Khanna Publishing, New Delhi, 411 p.

[5] Brida, J.G., Moreno-Izquierdo, L. and Zapata-Aguirre, S. (2016) Customer Perception of Service Quality: The Role of Information and Communication Technologies (ICTs) at Airport Functional Areas. Tourism Management Perspectives, 20, 209-216. https://doi.org/10.1016/j.tmp.2016.09.003

[6] Wicks, A.M. and Roethlein, C.J. (2009) A Satisfaction-Based Definition of Quality. Journal of Business and Economic Studies, 15, 82-97.

[7] Juran, J.M. and De Feo, J.A. (2010) Juran's Quality Handbook, The Complete Guide to Performance Excellence. 6th Edition. McGraw-Hill, New York.

[8] Cole, R.E. (1995) The Death and Life of the American Quality Movement. 1st Edition. Oxford University Press, New York.

[9] Crosby, P.B. (1989) Let's Talk Quality: 96 Questions You Always Wanted to Ask Phil Crosby. McGraw-Hill, New York.

[10] Speegle, M. (2010) Quality Concepts for the Process Industry. 2nd Edition. Delmar Cengage Learning, New York.

[11] Agency for Healthcare Research and Quality (2009) National Quality Measures 
Clearinghouse: Desirable Measure Attributes.

http://www.qualitymeasures.ahrq.gov/resources/measure_use.aspx\#attributes

[12] Vuk, T., Qiu, Y., Bust, L., Strengers, P. and Seidl, C. (2018) Quality Monitoring and Risk Management in Blood Transfusion Services. ISBT Science Series, 13, 284-289. https://doi.org/10.1111/voxs.12418

[13] International Organization for Standardization (2012) ISO 15189 Medical Laboratories: Requirements for Quality and Competence. 3rd Edition, International Organization for Standardization, Geneva.

[14] Shahangian, S. and Snyder, S.R. (2009) Laboratory Medicine Quality Indicators: A Review of the Literature. American Journal of Clinical Pathology, 131, 418-431. https://doi.org/10.1309/AJCPJF8JI4ZLDQUE

[15] Alain, C.B., Rostin, M.M.M., Joël, K.N.N., Hypolite, M.M., Donatien, K.N.-N., Koffi, T.A., Jérémie, M.M. and Hippolyte, S.N.-T. (2021) Evaluation of the Quality of Clinical Laboratory Services in the University Hospital of Kinshasa, Democratic Republic of the Congo. Journal of Economics and International Business Management, 9, 44-50. https://doi.org/10.33495/jeibm_v9i1.21.145

[16] Alain, C.B., Rostin, M.M.M., Joël, K.N.N., Hypolite, M.M., Donatien, K.N.-N., Koffi, T.A., Jérémie, M.M. and Hippolyte, S.N.-T. (2021) Evaluation of Clinical Laboratory Tests' Turnaround Time in a Tertiary Hospital in Democratic Republic of the Congo. Journal of Biosciences and Medicines, 9, 96-111. https://doi.org/10.4236/jbm.2021.97011

[17] Cameron, J. (2005) Focusing on the Focus Group. In: Hay, I., Ed., Qualitative Research Methods in Human Geography, 2nd Edition, Oxford University Press, Melbourne, 116-132.

[18] Guest, G., Namey, E. and McKenna, K. (2017) How Many Focus Groups Are Enough? Building an Evidence Base for Nonprobability Sample Sizes. Field Methods, 29, 3-22. https://doi.org/10.1177\%2F1525822X16639015

[19] Krueger, R.A. and Casey, M.A. (2009) Focus Groups: A Practical Guide for Applied Research. 4th Edition, SAGE Publications Inc., Thousand Oaks.

[20] Teich, S.T. and Faddoul, F.F. (2013) Lean Management-The Journey from Toyota to Healthcare. Rambam Maimonides Medical Journal, 4, e0007. https://doi.org/10.5041/RMMJ.10107

[21] Kitzinger, J. (1995) Qualitative Research: Introducing Focus Groups. BMJ, 311, 299-302. https://doi.org/10.1136/bmj.311.7000.299

[22] Kitzinger, J. (1994) The Methodology of Focus Groups: The Importance of Interactions between Research Participants. Sociology of Health and Illness, 16, 103-121. https://doi.org/10.1111/1467-9566.ep11347023

[23] Tates, K., Zwaanswijk, M., Otten, R., van Dulmen, S., Hoogerbrugge, P.M., Kamps, W.A., et al. (2009) Online Focus Groups as a Tool to Collect Data in Hard-to-Include Populations: Examples from Paediatric Oncology. BMC Medical Research Methodology, 9, Article No. 15. https://doi.org/10.1186/1471-2288-9-15

[24] World Health Organization. (2011) Laboratory Quality Management System: Handbook. WHO Press, Geneva.

[25] Clinical and Laboratory Standards Institute (2015) QMS16 Laboratory Personnel Management, 1st Edition, Wayne, Pennsylvania.

[26] Bates, I. and Maitland, K. (2006) Are Laboratory Services Coming of Age in SubSaharan Africa? Clinical Infectious Diseases, 42, 383-384.

https://doi.org/10.1086/499368 
[27] Muula, A.S. and Maseko, F.C. (2006) Medical Laboratory Services in Africa deserve more. Clinical Infectious Diseases, 42, 1503. https://doi.org/10.1086/503678

[28] Woodcock, S., Fine, G., McClure, K., Unger, B. and Rizzo-Price, P. (2010) The Role of Standards and Training in Preparing for Accreditation. American Journal of Clinical Pathology, 134, 388-392. https://doi.org/10.1309/AJCP03TFPBKEYYNT

[29] Njenga, MK., Traicoff, D., Tetteh, C., Likimani, S., Oundo, J., Breiman, R., et al. (2008) Laboratory Epidemiologist: Skilled Partner in Field Epidemiology and Disease Surveillance in Kenya. Journal of Public Health Policy, 29, 149-164. https://doi.org/10.1057/jphp.2008.3

[30] Swedberg, R., Michélsen, H., Chiriac, E.H. and Hylander, I. (2015) On-the-Job Training Makes the Difference: Healthcare Assistants' Perceived Competence and Responsibility in the Care of Patients with Home Mechanical Ventilation. Scandinavian Journal of Caring Sciences, 29, 369-378. https://doi.org/10.1111/scs.12173

[31] Abdel-All, M., Putica, B., Praveen, D., Abimbola, S. and Joshi, R. (2017) Effectiveness of Community Health Worker Training Programmes for Cardiovascular Disease Management in Low-Income and Middle-Income Countries: A Systematic Review. BMJ Open, 7, e015529. https://doi.org/10.1136/bmjopen-2016-015529

[32] Holihan, M.B. (2006) 365 Answers about Human Resources for the Small Business Owner. What Every Manager Needs to Know about Workplace Law. Atlantic Publishing Group Inc., Florida.

[33] World Health Organization (2010) WHO Guidelines on Drawing Blood: Best Practices in Phlebotomy. WHO-Press, Geneva.

[34] Liker, J.K. (2004) The Toyota Way: 14 Management Principles from the World's Greatest. McGraw-Hill Education, New York.

[35] Taylor, D.L. and Brunt, D. (2001) Manufacturing Operations and Supply Chain Management: The LEAN approach. 1st Edition. Cengage Learning EMEA, Beijing.

[36] Jones, D. and Womack, J. (2002) Seeing the Whole: Mapping the Extended Value Stream. Lean Enterprise Institute, Massachusetts.

[37] Rohani, J.M. and Zahraee, S.M. (2015) Production Line Analysis via Value Stream Mapping: A Lean Manufacturing Process of Color Industry. Procedia Manufacturing, 2, 6-10. https://doi.org/10.1016/j.promfg.2015.07.002

[38] Badiou, S., Vuillot, O., Bargnoux, A.S., Kuster, N., Lefebvre, S., Sebbane, M., et al. (2019) Improved Quality of Samples and Laboratory Turnaround Time Using 3.5 ml Low Vacuum BD Vacutainer ${ }^{\circledR}$ Barricor Tubes in the Emergency Department. Practical Laboratory Medicine, 16, e00128. https://doi.org/10.1016/j.plabm.2019.e00128

[39] Ramakers, C., Meyer, B., Yang, W., Plokhoy, E., Xiong, Y., Church, S., et al. (2019) Switching from Serum to Plasma: Implementation of BD Vacutainer ${ }^{\circledast}$ Barricor $^{\mathrm{TM}}$ Plasma Blood Collection Tubes Improves Sample Quality and Laboratory Turnaround Time. Practical Laboratory Medicine, 18, e00149. https://doi.org/10.1016/j.plabm.2019.e00149

[40] Moon, S.Y., Lee, H.S, Park, M.S., Kim, I-S. and Lee, S.M. (2021) Evaluation of the Barricor Tube in 28 Routine Chemical Tests and Its Impact on Turnaround Time in an Outpatient Clinic. Annals of Laboratory Medicine, 41, 277-284. https://doi.org/10.3343/alm.2021.41.3.277

[41] Hicks, J.M., Haeckel, R., Price, C.P., Lewandrowski, K. and Wu, A.H.B. (2001) Recommendations and Opinions for the Use of Point-of-Care Testing for Hospitals and Primary Care: Summary of a 1999 Symposium. Clinica Chimica Acta, 303, 1-17. https://doi.org/10.1016/S0009-8981(00)00400-9 
[42] Kendall, J., Reeves, B. and Clancy, M. (1998) Point-of-Care Testing: Randomized Controlled Trial of Clinical Outcome. BMJ, 316, 1052-1057. https://doi.org/10.1136/bmj.316.7137.1052

[43] Kilgore, M.L., Steindel, S.J. and Smith, J.A. (1998) Evaluating STAT Testing Options in an Academic Health Center: Therapeutic Turnaround Time and Staff Satisfaction. Clinical Chemistry, 44, 1597-1603. https://doi.org/10.1093/clinchem/44.8.1597

[44] Fernandes, C.M.B, Worster, A., Eva, K., Hill, S. and McCallum, C. (2006) Pneumatic Tube Delivery System for Blood Samples Reduces Turnaround Times without Affecting Sample Quality. Journal of emergency nursing, 32, 139-143. https://doi.org/10.1016/j.jen.2005.11.013

[45] Steindel, S.J. and Howanitz, P.J. (1997) Changes in Emergency Department Turnaround Time Performance from 1990 to 1993. A Comparison of Two College of American Pathologists Q-Probe Studies. Archives of Pathology \& Laboratory Medicine, 121, 1031-1041.

[46] Bany Hamdan, A., Aldakhil, A., Asiri, M., Tamani, J., Javison, S., Peethambaran, S., AlFayyad, I., Erlandez, R., AlKarim, H. and Al Harbi, M. (2018) The Effect of Satellite Laboratory Installation on Chemotherapy Waiting Time in an Oncology Treatment Unit. Cureus, 10, e2333. https://doi.org/10.7759/cureus.2333

[47] Leman, P., Guthrie, D., Simpson, R. and Little, F. (2004) Improving Access to Diagnostics: An Evaluation of a Satellite Laboratory Service in the Emergency Department. Emergency Medicine Journal, 21, 452-456.

[48] Dhatt, G., Manna, J., Bishawi, B., Chetty, D., Al Sheiban, A. and James, D. (2008) Impact of a Satellite Laboratory on Turnaround Times for the Emergency Department. Clinical Chemistry and Laboratory Medicine, 46, 1464-1467. https://doi.org/10.1515/CCLM.2008.290

[49] Lewandrowski, K. (2004) How the Clinical Laboratory and the Emergency Department Can Work Together to Move Patients through Quickly. Clinical Leadership \& Management Review, 18, 155-159.

[50] Jimmerson, C., Weber, D. and Sobek, D.K. (2005) Reducing Waste and Errors: Piloting Lean Principles at Intermountain Healthcare. The Joint Commission Journal on Quality and Patient Safety, 31, 249-257. https://doi.org/10.1016/S1553-7250(05)31032-4

[51] Curatolo, N., Lamouri, S., Huet, J.C. and Rieutord, A. (2014) A Critical Analysis of Lean Approach Structuring in Hospitals. Business Process Management Journal, 20, 433-454. https://doi.org/10.1108/BPMJ-04-2013-0051

[52] Rutman, L., Stone, K., Reid, J., Woodward, G.A.T. and Migita, R. (2015) Improving Patient Flow Using Lean Methodology: An Emergency Medicine Experience. Current Treatment Options in Pediatrics, 1, 359-371.

https://doi.org/10.1007/s40746-015-0038-0 